\title{
АУГМЕНТАЦИОННАЯ МАММОПЛАСТИКА
}

СЕРГЕЙ АЛЕКСАНДРОВИЧ ОБЫДЕННОВ, канд. мед. наук, доц. кафедры оперативной хирургии и топографической анатомии ГОУ ВПО «Казанский государственный медицинский университет Росздрава», главный врач Клиники эстетической медицины [(843) 2989204, e-mail: sergey@medclinica.ru]

Реферат. Были проанализированы результаты аугментационной маммопластики у 240 пациенток, выполненной различными доступами. Аугментация - это увеличение молочных желез с помощью имплантов. Сегодня в пластической хирургии увеличение груди не считается сложной операцией. Отработанные методики позволяют быстро провести увеличение груди.

Ключевые слова: аугметационная маммопластика, грудь, импланты.

\section{AUGMENTATION MAMMOPLASTY}

\section{S.A.OBYDENNOV}

Abstract. Results of the augmentation of the breast in 240 patients, using different approaches were analyzed. Augmentation - this is augmentation of the breast with implants. Now in plastic surgery augmentation mammaplasty is not a difficult operation. Contemporary methods allow conducfing the augmentation of the breast quickly.

Key words: augmentation mammaplasty, breast, implants.

$\mathrm{B}$ ведение. Около 40\% женщин мечтают произвести увеличение груди. Грудь - самая волнующая и интригующая часть женского тела. Это не просто дар природы, это предмет гордости, часто - зависти, иногда - восхищения не только самих женщин, но и мужчин, старающихся украдкой остановить свой взгляд на этом бесценном капитале. Но, увы, природа жестока, она не всегда равномерно одаривает всех представительниц прекрасного пола столь же прекрасными формами. Иногда прежде идеальные формы с годами теряют свою привлекательность. Причиной ухудшения состояния груди может являться резкое похудение, возрастные изменения, беременность и кормление малыша. Восстановить форму, минуя эндопротезирование молочных желез, сложно и практически невозможно. Что делать? Выходов несколько. Можно не обращать на это внимания, смириться, радоваться тому, что растут дети и внуки, носить необлегающую одежду и прибегать к разным женским хитростям при общении с мужчинами. Но не все согласны с подобным взглядом на свое существование. Самые энергичные и жизнелюбивые женщины идут на консультацию к пластическому хирургу. На прием к хирургу-пластику приходят женщины с разными проблемами, касающимися пластики груди.

Материал и методы. Нами за период с 2005 г. по 2009 г. выполнено 240 увеличивающих маммопластик пациенткам в возрасте от 17 до 43 лет (средний возраст 26 лет). Для проведения эндопротезирования молочных желез обычно используется 3 способа хирургического доступа: через область подмышки (подмышечный доступ), в грудную складку (субмаммарный доступ), вокруг соска (параареолярный доступ) (рис. 1). Во всех случаях нами использовались протезы фрирмы «Ментор», текстурированные, в $9(3,75 \%)$ случаях - анатомические, в остальных - круглые (96,25\%). Объем имплантнов был от 180 до 800 мл. Импланты размещались под большой грудной мышцей в 2 плоскостях по Tebbets (2006), т.e. 2/3 импланта под большой грудной мышцей, 1/3 в мягких тканях у $212(87,3 \%)$ пациенток, у остальных субгландулярно (12,7\%). Среднее время наблюдения составило 23 мес (общее время наблюдения от 3 до 40 мес).
Предоперационное планирование. В день операции все пациентки обязательно фотографировались в фрас, профиль и с разворотом на $45^{\circ}$ слева и справа. В вертикальном положении пациенткам измерялось расстояние от яремной вырезки, от средней линии и от среднеключичной линии до сосков, оценивалась толщина и состояние покровных тканей молочных желез (если толщина клетчатки была 1 см и менее, то протезы размещались субмускулярно), размеры и местоположение ареол относительно друг друга, планировалась плоскость диссекции. Выполнялась разметка на молочных железах, отмечались средняя и среднеключичная линии, положение новой субмаммарной складки, будущее место расположения имплантов.

Все пациентки условно были разбиты на 3 группы. К I группе были отнесены 2 пациентки, которым устанавливались протезы из подмышечного доступа. Были

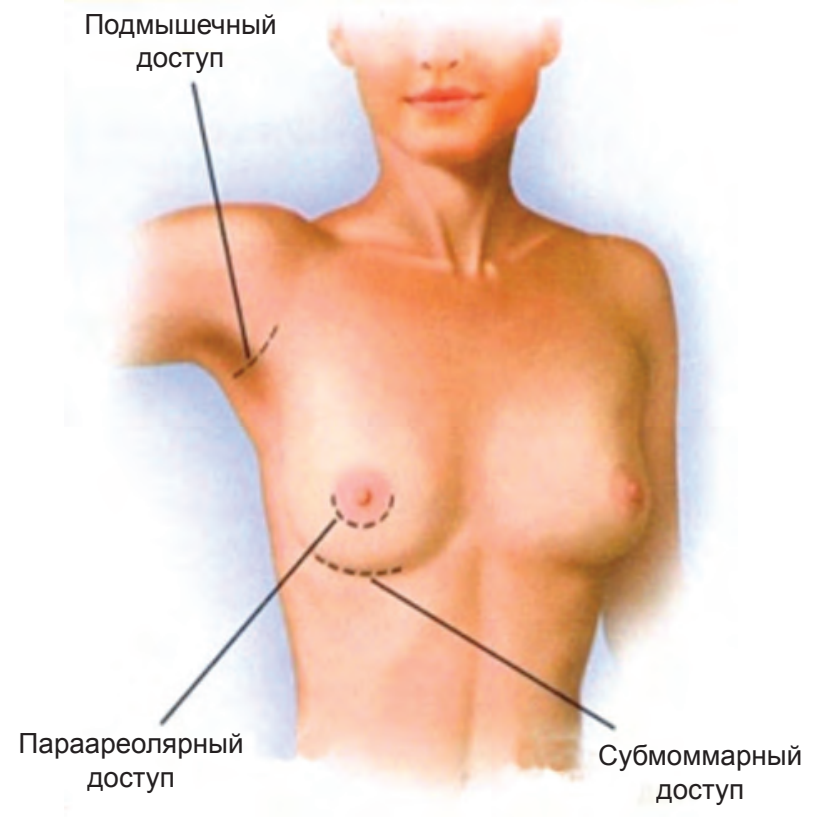

Рис. 1. Различные виды доступов для установки имплантов 
установлены протезы 180 и 200 мл. В этом случае протезы всегда устанавливались под мышцу.

Ко II группе были отнесены пациентки, которым протезы были установлены через субмаммарный доступ рубец в складке под молочной железой. Протезы от 180 до 800 мл. В этой группе пациенток у 50 были созданы карманы для протезов субгландулярно, у 62 - в 2 плоскостях.

В III группу включены пациентки, которым произведен параареолярный доступ. Им установлены протезы объемом $200-450$ мл. В 10 случаях карманы созданы субгландулярно, у 116 пациенток в 2 плоскостях.

Разделение пациенток было выполнено для удобства систематизации и носило условный характер.

Техника операций. Все операции выполнялись под общей анестезией. У пациенток I группы разрез кожи выполнялся по внутреннему краю большой грудной мышцы на границе с волосистой частью [1]. Обычно разрез не превышал $3 \mathrm{~cm}$.

У пациенток II группы разрез выполнялся в существующей субмаммарной складке длиной до 5 см. Через него создавался карман либо субгландулярно, либо субмускулярно, либо в 2 плоскостях [2].

B III группе разрез выполнялся по нижнему внутреннему, реже наружному краю ареолы и занимал, как правило, не более половины длины окружности ареолы. Впервые данный доступ описан в начале 1970-х гг. [3, 4]. Если ареола была небольшая, то дополнительно деэпидермизировался участок непигментированной кожи в виде эллипса шириной до 1 см. В дальнейшем диссекция мягких тканей молочной железы осуществлялась через паренхиму железы, перпендикулярно основанию. Затем фрормировали карман для протезов, который в зависимости от состояния тканей, формы и толщины молочный железы создавали под железой, в 2 плоскостях или под большой грудной мышцей с обязательным отсечением ее грудинного сращения на 3-4 см снизу. После выполнения гемостаза в сформированный карман устанавливался соответствующих размеров имплант. Рассеченные края паренхимы сшивались непрерывными швами $3 / 0$. Кожа ушивалась внутрикожными швами также Vicryl 6/0. Практически во всех группах в сформированную полость устанавливался резиновый дренаж, который удалялся на следующие сутки после операции.

Послеоперационный период. В послеоперационном периоде все пациентки носили компрессионный бюстгальтер фрирмы Byron или Native в течение 1 мес. Всем оперированным назначали стандартную противовоспалительную, противоотечную и обезболивающую терапию. Мыться разрешали на 3-й день после операции. Приступать к физическим нагрузкам через 1,5-2 мес, к повседневным нагрузкам - через неделю.

Результаты и их обсуждение. Результаты выполненных операций прослежены у 185 пациенток в сроки от 3 до 40 мес. Капсулярная контрактура III—IV степени (по Baker) возникла у 2 пациенток, которым карманы для протезов были созданы под железой. В обоих случаях была выполнена корригирующая операция - капсулотомия, с установкой имплантов под мышцу. Одной пациентке протезы через 8 лет после установки были удалены по ее настоянию, хотя никаких осложнений не было, а эстетический результат был хороший, он удовлетворял и пациентку (она врач), и нас.

Нам не понравились эстетические результаты в I группе (рис. 2). Во-первых, расстояние между молочными железами было большое, во-вторых, рубец в подмышечной впадине всегда виден при подъеме рук, тем

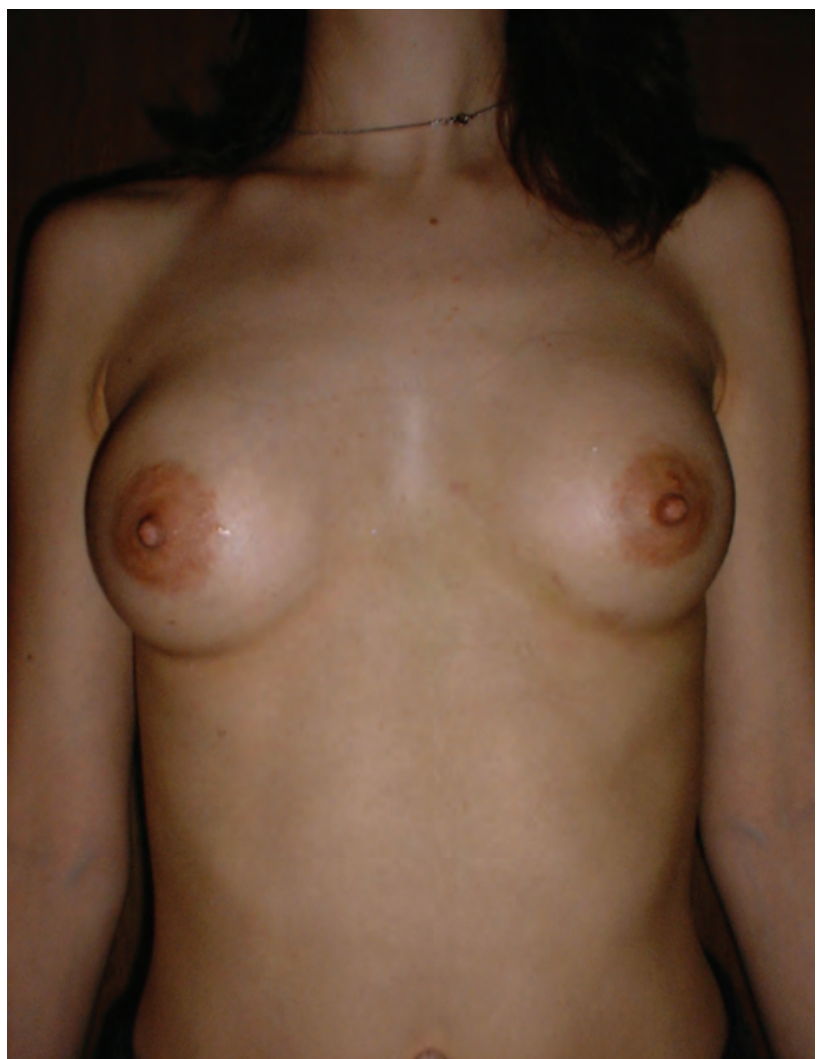

Рис. 2. Установка имплантов через подмышечный доступ субмускулярно. Объем имплантов 200 мл, текстурированные, круглые, низкий профиль, фрирма «Ментор». До операции (слева), через неделю после операции (справа). Послеоперационных рубцов на молочных железах нет 
более что пациентки сбривают волосы в подмышечной области.

Bo II группе эстетический результат более приемлем, поскольку в бюстгальтере или купальнике рубца в суб-

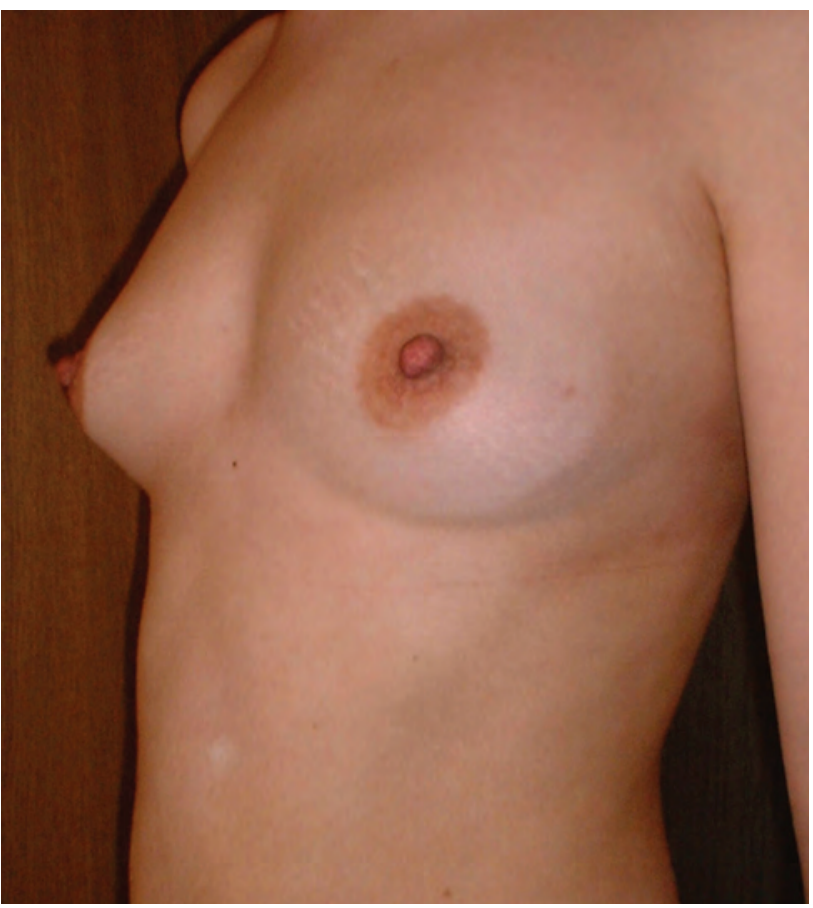

маммарной складке не видно (рис. 3, 4), но его, по нашему мнению, нельзя применять у пациенток, у которых субмаммарная складка отсутствует из-за полной аплазии молочных желез (рис. 5).

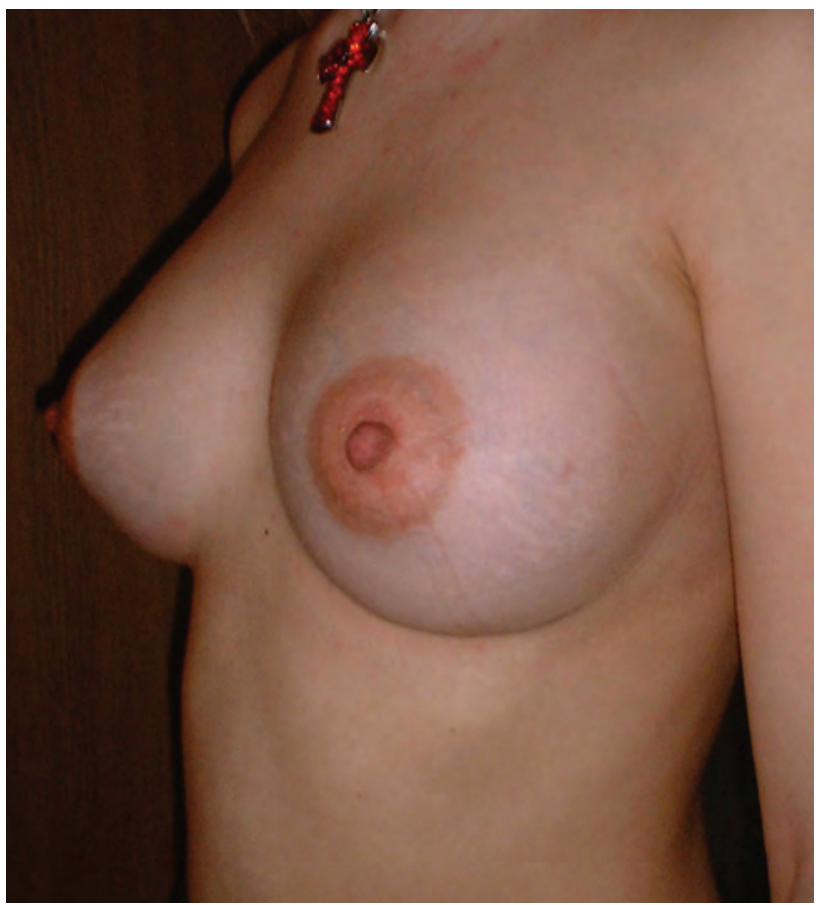

Рис. 3. Установка протезов через субмаммарный доступ субгландулярно. Объем имплантов 300 мл, текстурированные, круглые, средний профиль, фирма «Ментор». До операции (слева), через 1 год после операции (справа).

В вертикальном положении пациентки рубцы не видны
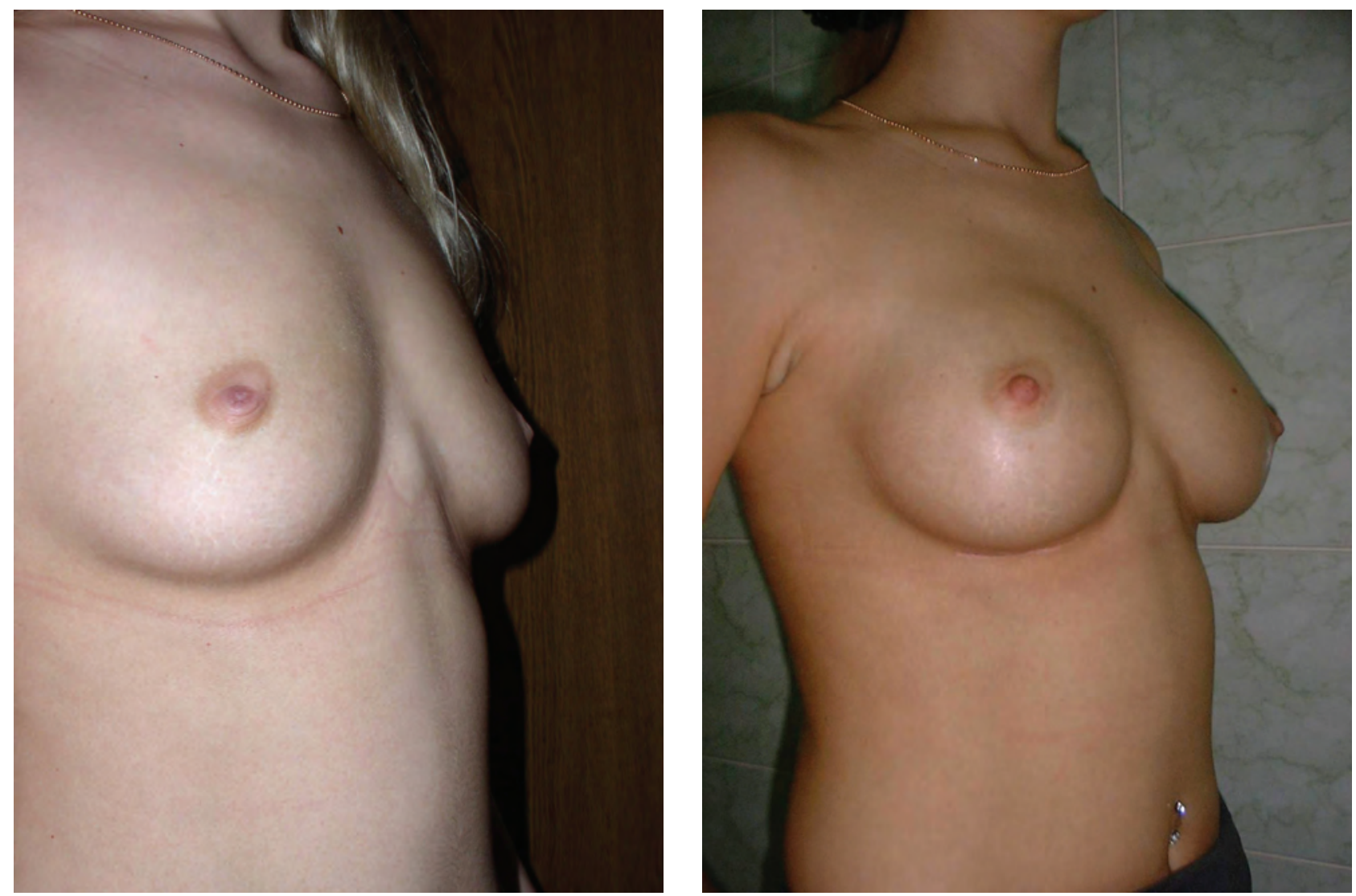

Рис. 4. Установка протезов через субмаммарный доступ субгландулярно. Объем имплантов 300 мл, текстурированные, анатомические, средний профиль, фирма «Ментор». До операции (слева), через 1 год после операции (справа). Положение пациентки с выгнутой спиной и поднятым плечевым поясом: только в этом положении виден послеоперационный рубец 

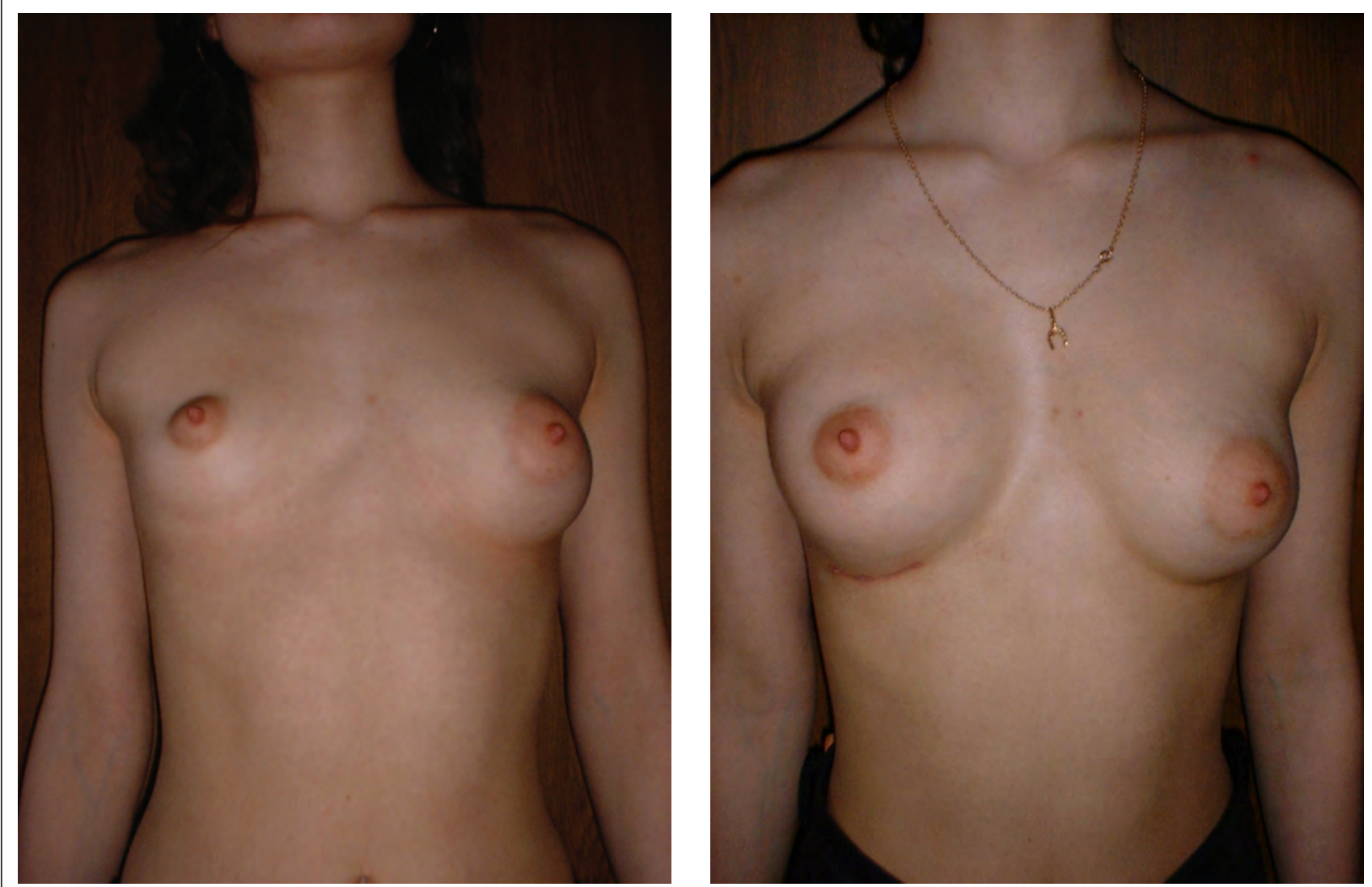

Рис. 5. Установка протеза через субмаммарный доступ субмускулярно с одной стороны при синдроме Поланда. Объем импланта 225 мл, текстурированный, анатомический, средний профиль, фирма «Ментор». До операции (слева), через 2 мес после операции (справа). Видимый послеоперационный рубец под грудью при отсутствии субмаммарной складки
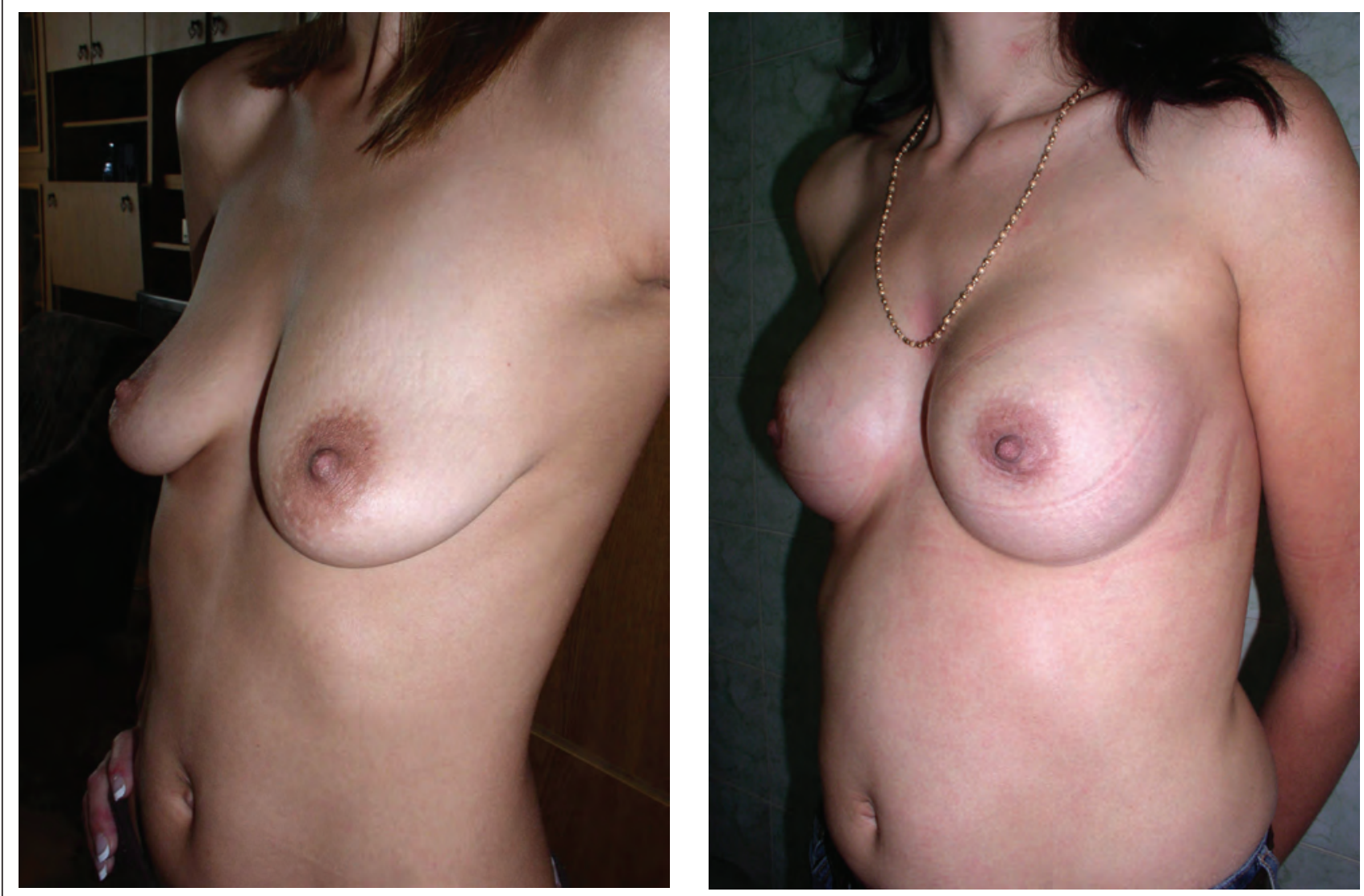

Рис. 6. Установка протеза через параареолярный доступ. Объем импланта 325 мл, текстурированный, анатомический средний профиль, фрирма «Ментор». До операции (слева), через 2 года после операции (справа) 

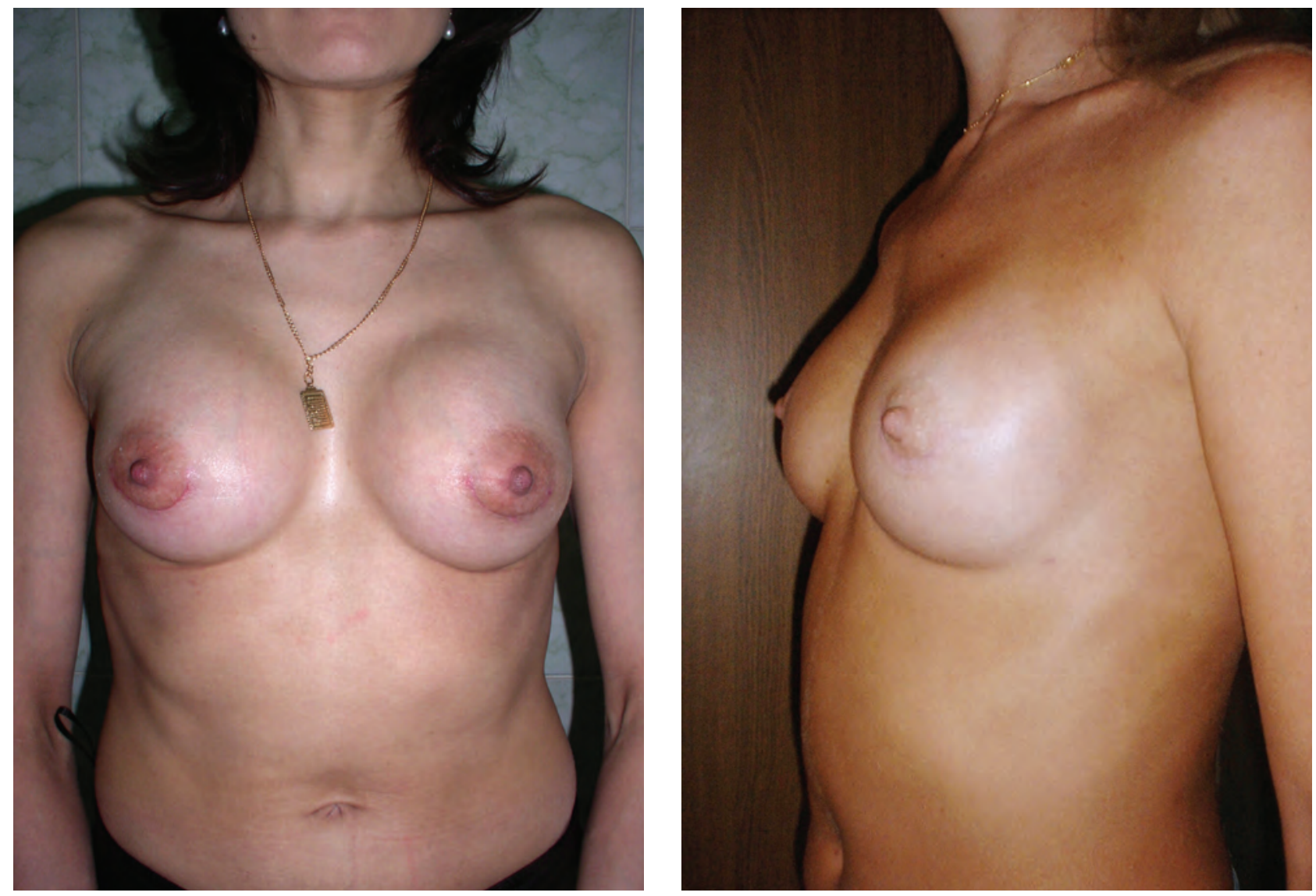

Рис. 7. Установка имплантов через параареолярный доступ. Слева пациентка через 3 нед после установки текстурированных круглых имплантов, средний профриль, фирма «Ментор», объем 275 мл. Послеоперационные рубцы еще видны. Справа через

3 мес после установки текстурированных анатомических имплантов, низкий профильь, фирма «Ментор», объем 180 мл.

Послеоперационные рубцы уже практически не видны

Нам больше всего нравится параареолярный доступ. По-нашему мнению, он является превосходным доступом для увеличения груди. Он очень удобен при постановке как анатомических, так и круглых имплантов любого профиля (рис. 6, 7).

Благодаря своему расположению он незаменим при небольшой аугментации у пациенток с отсутствием видимой субмаммарной складки. Используя его, можно выполнить смещение ареол для коррекции асимметрии положения и параареолярную мастопексию. Параареолярный доступ позволяет выполнить аугментацию из центральной части молочной железы, легко и точно выполнить создание кармана для протеза в необходимой плоскости во всех направлениях [5] с малозаметным рубцом после операции [6, 7]. Травмирование паренхимы молочной железы на практике редко влечет за собой какие-либо проблемы как клинически, так и рентгенологически $[8,9]$.

\section{ЛИТЕРАТУРА}

1. Исмагилов, А.Х. Транаксиллярная субпекторальная аугментационная маммопластика с видиоассистенцией/ А.Х. Исмагилов, Р.Ш. Хасанов, Х.М. Губайдуллин, А.М. Гимранов
// Анналы пластической, реконструктивной и эстетической хирургии. - 2008. - Т.3 (прил.). - С. 179-180.

2. Белоусов, А.Е. Пластическая реконструктивная и эстетическая хирургия / А.Е. Белоусов. —СПб., 1998.

3. Jenny, H. Areolar approach to augmentation mammaplasty/ H. Jenny // Plast. Reconsr. Surg. - 1974. - Vol. 53. P. 344.

4. Jones, F.R. A periareolar incision for augmentation mammaplasty/ F.R. Jones, A.P. Tauruas // Plast. Reconsr. Surg. — 1973. Vol. 51. - P. 641

5. Spear, S.L.The medial periareolar approach to submuscular augmentation mammaplasty under local anaesthesia / S.L. Spear, H. Matsuba, J.W. Little // Plast. Reconsr. Surg. 1989. - Vol. 84. - P. 399.

6. Candiani, P. Augmentation mammaplasty: Personal evolution on the concept looking for an ideal technigue / P. Candiani, G.L. Capiglio // Aesthetic plast. Surg. — 1997. — Vol. 21. P. $417-422$.

7. Hidalgo, D.A. Breast augmentation: Choosing the optimal incision, implant and pocket plane/ D.A. Hidalgo // Plast. Reconsr. Surg. - 2000 - Vol. 105. - P. 2002.

8. Courtiss, E.H. Breast sensation before and after plastic surgery / E.H. Courtiss, R.M. Goldvin // Plast. Reconsr. Surg. — 1979. Vol. 58. - P. 1.

9. Stoff-Khalili, M.A. Subfascial periareolar augmentation mammaplasty / M.A. Stoff-Khalili, R. Scholze, R.M. William // Plast. Reconsr. Surg. — 2004. — Vol. 114. - P. 1280. 